\title{
A Power Converter Decoupled from the Resonant Network for Wireless Inductive Coupling Power Transfer
}

\author{
Lin Chen ${ }^{1,2}$, Jianfeng Hong ${ }^{1,3,4}$, Mingjie Guan ${ }^{1}$, Wei Wu ${ }^{1,5}$ and Wenxiang Chen ${ }^{1,3,4, *}$ \\ 1 Department of Instrumental and Electrical Engineering, Xiamen University, Xiamen 361005, China;

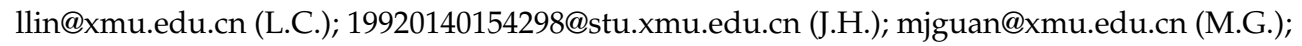 \\ 19920130154221@stu.xmu.edu.cn (W.W.) \\ 2 Department of Biological System Engineering, Washington State University, Pullman, WA 99164, USA \\ 3 Fujian Collaborative Innovation Center for R\&D of Coach and Special Vehicle, Xiamen 361024, China \\ 4 Fujian Key Laboratory of Advanced Design and Manufacture for Bus\$Coach, Xiamen 361024, China \\ 5 School of Mechanical and Electrical Engineering, Guizhou Normal University, Guiyang 550001, \\ Guizhou, China \\ * Correspondence: wxchen@xmu.edu.cn; Tel.: +86-0592-218-7512
}

Received: 13 February 2019; Accepted: 22 March 2019; Published: 27 March 2019

\begin{abstract}
In a traditional inductive coupling power transfer (ICPT) system, the converter and the resonant network are strongly coupled. Since the coupling coefficient and the parameters of the resonant network usually vary, the resonant network easily detunes, and the system efficiency, power source capacity, power control, and soft switching conditions of the ICPT system are considerably affected. This paper presents an ICPT system based on a power converter decoupled from the resonant network. In the proposed system, the primary inductor is disconnected from the resonant network during the energy injection stage. After storing a certain amount of energy, the primary inductor is reconnects with the resonant network. Through this method, the converter can be decoupled from the resonant network, and the resonant network can be tuned under various coupling coefficients. Theoretical analysis was explored first. Simulations and experimental work are carried out to verify the theoretical analysis. The results show that the proposed ICPT system has the virtues of low power source capacity, independent power control, and soft switching operation under different coupling coefficients.
\end{abstract}

Keywords: inductive coupling power transfer; decoupled; energy injection; soft switching; efficiency

\section{Introduction}

Since the late 2000s, inductive coupling power transfer (ICPT) has been widely used for wireless energy transmission over large air gaps [1-5]. Due to its safety and convenience, ICPT is a promising method for charging electrical vehicles (EVs) [6,7]. However, during the charging process, the ICPT system faces problems such as the varying load from the changed state of charge (SOC) of the batteries [8], coil misalignment [9], and the varying air gap, either of which will lead to changes in the electromagnetic characteristics and coefficients [6,10]. All these issues can be attributed to the problem caused by changes in the coupling coefficient, which should be considered in the design of an ICPT system.

To achieve optimal output power and efficiency, it is necessary to adjust the frequency of the power converter, according to the changes in the system parameters [11-13]. Many impedance reconfiguration methods have been introduced for frequency tracking in ICPT [14-17]. Hsu and Hu [15] adopted an LCL structure with a variable inductance. By changing the value of the variable inductance, the 
ICPT system was retuned. In Kamineni et al. [16], a switchable bank of capacitors consisting of four capacitors with a ratio of 1:2:4:8 was employed, producing 16 different capacitance combinations to adjust the frequency.

Using a phase-locked loop (PLL) and by tracking the zero-phase angle of the voltage and current, the ICPT system could automatically track the optimal frequency [18-20]. Matysik [18] introduced the application of a phase controller that can adjust the phase shift of the current and voltage in a resonant tank with no periodic voltage waveform. Gati et al. [19] employed a digital PLL to decrease the phase shift between the secondary current and the inverter output voltage by adjusting the inverter frequency.

By using a self-oscillating switching technique in the control of the inverter, output controllability, dynamic response, and self-adaptability can also be improved [21-23]. In Xu et al. [21], by detecting the zero-crossing point of secondary current, a series-series converter was used to automatically adjust the frequency and obtain better self-adaptability under different air gaps. Namadmalan et al. [22] applied a one-third clock divider behind the zero-crossing comparator. The system was able to switch between fundamental and third-harmonic modes for different load and coupling conditions.

As a strong coupling exists between the power source, the converter, and the resonant tank, the traditional ICPT system is a high-order system. The transient process involved in this type of system is usually complex and hard to analyze [24]. Based on a separated energy injection and free oscillation strategy $[24,25]$, the power source can be decoupled from the resonant tank during a free oscillation period. However, the coupling between the power supply and the resonant tank still exists in the energy injection period.

Li et al. [25] provided an energy injection and free oscillation strategy for a direct AC-AC converter. When the converter is in a resonance state, the resonant tank is completely isolated from the power source and the system can be described as a second-order system. However, in their system, the energy injection can only start at the positive zero-crossing moment of the primary current in each half-cycle. Therefore, an integrated control method [26] should be used to control the switches of the converter. The integrated control method needs complex control circuit and control process, which is difficult to apply in practical applications.

Power control plays an important role in the ICPT system [27]. Traditional power control methods include phase shifting, frequency control, and reactive power control. These power control methods, however, may result in an increase in switching losses and electromagnetic noise due to the difficulty for switching devices to be always turned on and off at zero current point $[28,29]$. The energy injection and free oscillation strategy control the power by using the cycle number of the injected energy under a resonant state, and the converter drives a purely resistive load. All switching devices in this strategy operate under zero-current switching conditions $[24,25]$. This strategy can solve the problems caused by the traditional power control methods. However, in an energy injection and free oscillation ICPT system, the resonant tank cannot be decoupled from the converter during the energy injection period. Therefore the converter frequency should be the same as the resonant frequency. In practical applications, when the coupling coefficient and load changed, the system will detune, and the reflected impedance from the secondary part may be reactive, which make the equivalent primary impedance complex [24]. The converter must drive an additional reactance. And the converter cannot inject energy efficiently in the positive half cycle, which complicates power control in practical applications.

This paper presents an ICPT system with a two-stage energy injection and self-tuning (TSEIST) control strategy. In the proposed system, the primary inductor is disconnected with the resonant network and connected with the power source in the energy injection stage. In the self-tuning stage, the primary inductor is reconnected with the resonant network for self-tuning. As such, the power converter can be completely decoupled from the resonant network and independently inject energy into the primary inductor. Since the energy injection is independent, the converter frequency need not be the same as the resonant tank frequency, and the power can be controlled independently. In the TSEIST ICPT system, the power can be controlled only by the energy injection time. Compared with traditional tuning methods, this method reduces the difficulties of power control. 
In a traditional system, to ensure soft switching conditions, it is necessary to use complex control circuits, such as zero-crossing switching or an integrated control method. In the proposed system, switching time margins are applied to ensure soft switching conditions. The time margins allow the switch operations acted within a time period, but not at a time moment, which reduces the switching control difficulty and the circuit complexity. Thus, in the TSEIST ICPT system, the system can be tuned under various coupling coefficients.

\section{Basic Structure and System Modeling}

\subsection{Structure of the TSEIST ICPT System}

An AC-DC converter system using an energy injection and free oscillation strategy is shown in Figure 1a [26]. According to the polarity of the input voltage, switch $S_{1}$ or $S_{2}$ is turned on for energy injection. The bidirectional switches $S_{3}$ and $S_{4}$ are turned on during the free oscillation stage. Note that switches $S_{3}$ and $S_{4}$ should not be turned on simultaneously with $S_{1}$ and $S_{2}$ in case of a short circuit. The resonant tank is on the right part of the circuit, in which $C_{p}$ is the tank capacitor, $L_{p}$ is the primary inductor and $Z_{\mathrm{r}}$ is the impedance reflected from the secondary to the primary part. A strong coupling exists between the resonant tank and the converter during the energy injection period. In this system, when reactive components are involved in the reflected impedance, the converter will not effectively inject energy.

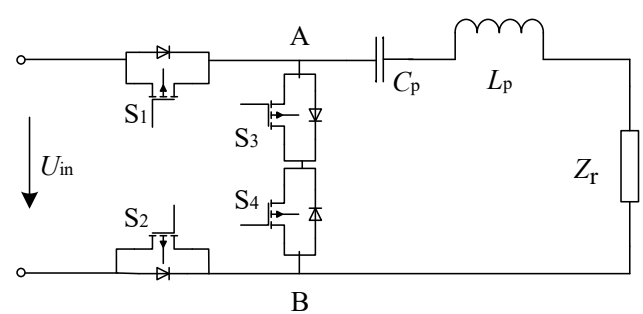

(a)

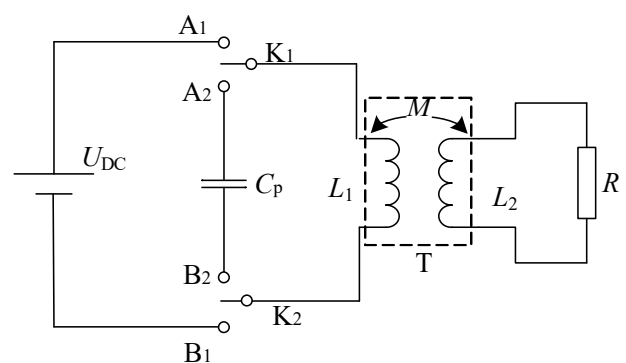

(b)

Figure 1. Comparison of two topologies: (a) the energy injection and free oscillation system [26]; (b) the proposed two-stage energy injection and self-tuning (TSEIST) inductive coupling power transfer (ICPT) system.

A topology of the proposed TSEIST ICPT system is shown in Figure 1b. It consists of a power source $U_{\mathrm{DC}}$, a loosely coupled transformer $\mathrm{T}\left(L_{1}\right.$ is the primary inductor and $L_{2}$ is the secondary inductor), a resonant capacitor $C_{\mathrm{p}}$, two double-throw switches $\left(\mathrm{K}_{1}, \mathrm{~K}_{2}\right)$, and the load resistance $R$. The mutual inductance of the loosely coupled transformer is $\mathrm{M}$.

Different from the traditional ICPT system, the TSEIST ICPT system is based on the double-throw switches, $K_{1}$ and $K_{2}$. When $K_{1}$ is connected to $A_{1}$ and $K_{2}$ is connected to $B_{1}$, the primary inductor $L_{1}$ is connected to the power source, and the system is in the energy injection stage. When $\mathrm{K}_{1}$ is connected to $A_{2}$ and $K_{2}$ is connected to $B_{2}$, the primary inductor $L_{1}$ is connected to the resonant capacitor $C_{p}$, and the system is in the free oscillation stage. Under this strategy, $L_{p}$ is connected to the power source only during the energy injection stage, and the converter is completely decoupled from the resonant tank. According to the connection states of $K_{1}$ and $K_{2}$, the TSEIST system can work in three stages:

(1) Energy injection stage. In this stage, $K_{1}$ and $K_{2}$ connect to $A_{1}$ and $B_{1}$, respectively. $U_{D C}$ is connected to $L_{1}$ and injects energy into the primary coil. In this process, part of the energy is transferred to the secondary coil.

(2) Self-tuning stage. In this stage, $K_{1}$ and $K_{2}$ connect to $A_{2}$ and $B_{2}$, respectively. $C_{p}$ is connected to $L_{1}$ to form a resonant tank and the system begins to resonate. The energy continues to be transferred to the secondary coil. 
(3) Shutdown stage. $K_{1}$ and $K_{2}$ are switched to the center point, where $U_{\mathrm{DC}}, C_{\mathrm{p}}$, and $L_{1}$ are isolated from each other. In this stage, the system stops transferring energy to the secondary part and the remaining energy is stored in the capacitor $C_{p}$ as electrical energy.

In real applications, skipping the shutdown stage is desirable to enhance the output power. In that case, the proposed converter becomes a two-stage converter.

\subsection{System Modeling}

\subsubsection{Energy Injection Stage}

In this stage, the system can be described as a first-order system and can be simplified as shown in Figure 2a, where $N_{1}$ and $N_{2}$ are the turns of the primary and the secondary coil, respectively; $L_{1}$ is the primary inductance; and $L_{2}$ is the secondary inductance. The loosely coupled transformer can be equivalent to a T model circuit, as shown in Figure $2 \mathrm{~b}$.

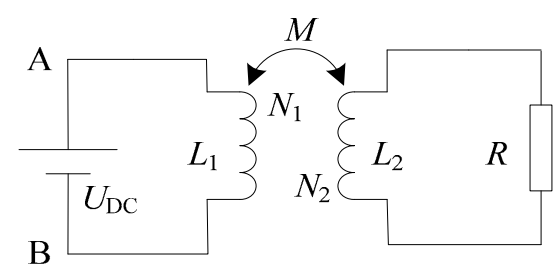

(a)

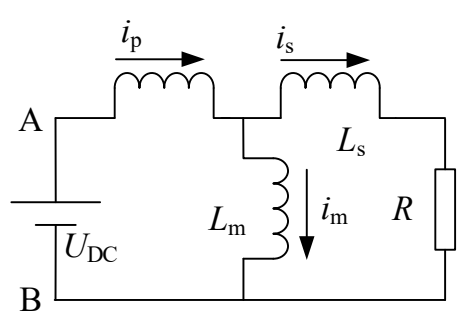

(b)

Figure 2. Circuit models in the energy injection stage: (a) simplified circuit model; (b) equivalent circuit model.

In Figure $2 \mathrm{~b}, L_{\mathrm{p}}$ is the primary leakage inductance; $L_{\mathrm{s}}$ is the secondary leakage inductance; and $L_{\mathrm{m}}$ is the magnetizing inductance. For simplicity, in this paper, $N_{1}=N_{2}$ and $L_{1}=L_{2}=L$. The coupling coefficient $k$ is defined as $k=M \times\left(L_{1} \times L_{2}\right)^{-1 / 2}$. Then, we obtain:

$$
\left\{\begin{array}{c}
L_{p}=L_{s}=L-M=(1-k) L \\
M=L_{m}=k L
\end{array} .\right.
$$

\subsubsection{Self-Tuning Stage}

In this stage, the loosely coupled transformer is equivalent to the $M$ model as in Figure $3 a$, and the primary loop impedance can be obtained as:

$$
Z_{p}=\frac{R \omega^{2} k^{2} L^{2}}{R^{2}+\omega^{2} L^{2}}+j \omega\left(1-\frac{k^{2} \omega^{2} L^{2}}{R^{2}+\omega^{2} L^{2}}\right) L
$$

where $\omega$ is the resonant frequency.

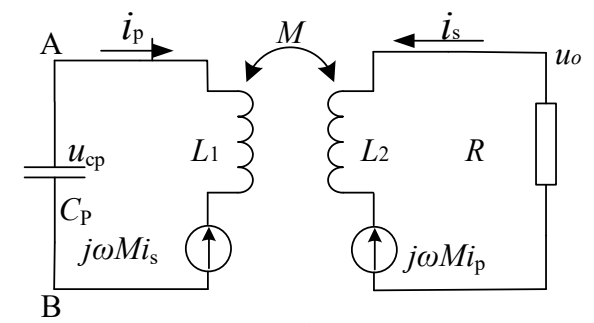

(a)

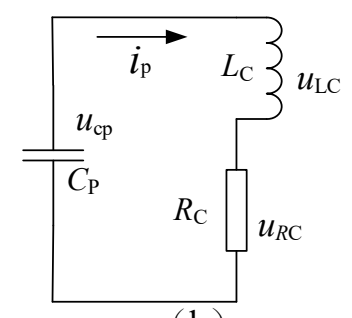

(b)

Figure 3. Circuit models in the self-tuning stage: (a) T model; (b) simplified model. 
The real part is the equivalent load and can be expressed as $R_{\mathrm{C}}$. Thus:

$$
R_{\mathrm{C}}=\operatorname{Re}\left\{Z_{\mathrm{p}}\right\}=\frac{R \omega^{2} k^{2} L^{2}}{R^{2}+\omega^{2} L^{2}} .
$$

The imaginary part is the total reactance of the system. It contains the primary reactance of inductance $L_{1}$ and the reactance reflected from secondary inductance $L_{2}$. Thus:

$$
X_{\mathrm{p}}=\mathrm{I}_{m}\left\{Z_{\mathrm{p}}\right\}=\omega\left(1-\frac{k^{2} \omega^{2} L^{2}}{R^{2}+\omega^{2} L^{2}}\right) L=\omega L_{c} .
$$

According to Equations (3) and (4), the equivalent circuit model during the self-tuning stage can be obtained as shown in Figure $3 \mathrm{~b}$. In Figure $3, i_{\mathrm{p}}$ is the primary inductive current and $i_{\mathrm{s}}$ is the secondary inductive current.

\section{TSEIST Converter}

\subsection{Topology of the TSEIST Converter}

The TSEIST converter structure is shown in Figure 4. The converter consists of a modified $\mathrm{H}$ bridge. $S_{1}$ and $S_{2}$ correspond to the top switch of the lead bridge. $S_{3}$ corresponds to the down switch of the lead bridge. $S_{4}$ and $S_{5}$ correspond to the top switch of lag bridge. And $S_{6}$ corresponds to the down switch of the lag bridge. The primary inductor $L_{1}$ is connected to points $\mathrm{A}$ and $\mathrm{B}$ of the modified $\mathrm{H}$ bridge. Switches $\mathrm{S}_{1}, \mathrm{~S}_{2}, \mathrm{~S}_{4}$, and $\mathrm{S}_{5}$ construct a sub-H bridge, which plays the roles of $\mathrm{K}_{1}$ and $\mathrm{K}_{2}$ in Figure $1 \mathrm{~b}$. The tank capacitance $C_{\mathrm{p}}$ is connected to points $\mathrm{C}$ and $\mathrm{D}$ in the sub- $\mathrm{H}$ bridge. By controlling the switches $S_{2}$ and $S_{5}, C_{p}$ can be connected or disconnected to $L_{1}$.

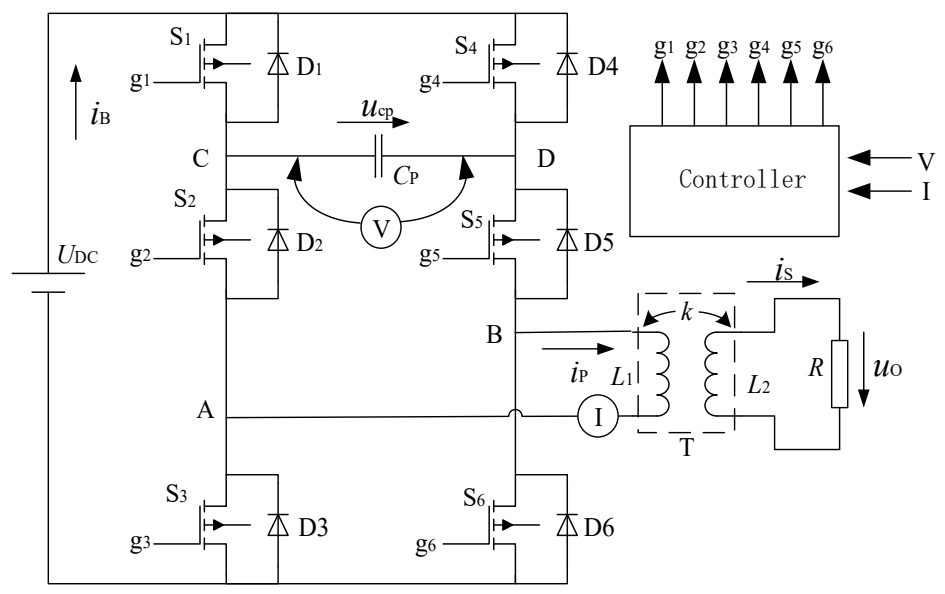

Figure 4. Structure of the TSEIST power converter.

In Figure 4, a controller is needed to control the switches $\mathrm{S}_{1-6}$. A voltage sensor is in parallel with $C_{\mathrm{p}}$ to measure the voltage $u_{\mathrm{cp}}$. A current sensor is in series with $L_{1}$ to measure the current $i_{\mathrm{p}}$. The signals obtained from the sensors are sent to the controller. The controller creates a control strategy to switch the system within the three stages described above.

\subsection{State Analysis}

The working process of the proposed power converter can be divided into positive and reverse energy transmission periods, which can be further divided into 10 working states, including 6 main states and 4 transitional states, as shown in Figure 5. For clarity, in Figure 5, the loosely coupled transformer $T$ and the load resistor $R$ in Figure 4 are replaced by $L_{C}$ and $R_{C}$, respectively, as shown in Figure $3 b$. The states are continuously numbered and illustrated with schematic circuits. The on-state 
switching devices and branches are denoted with bold solid black lines. The off-state switching devices and branches are denoted with dotted lines. The directions of currents and the polarities of the voltages are also shown in the figure.

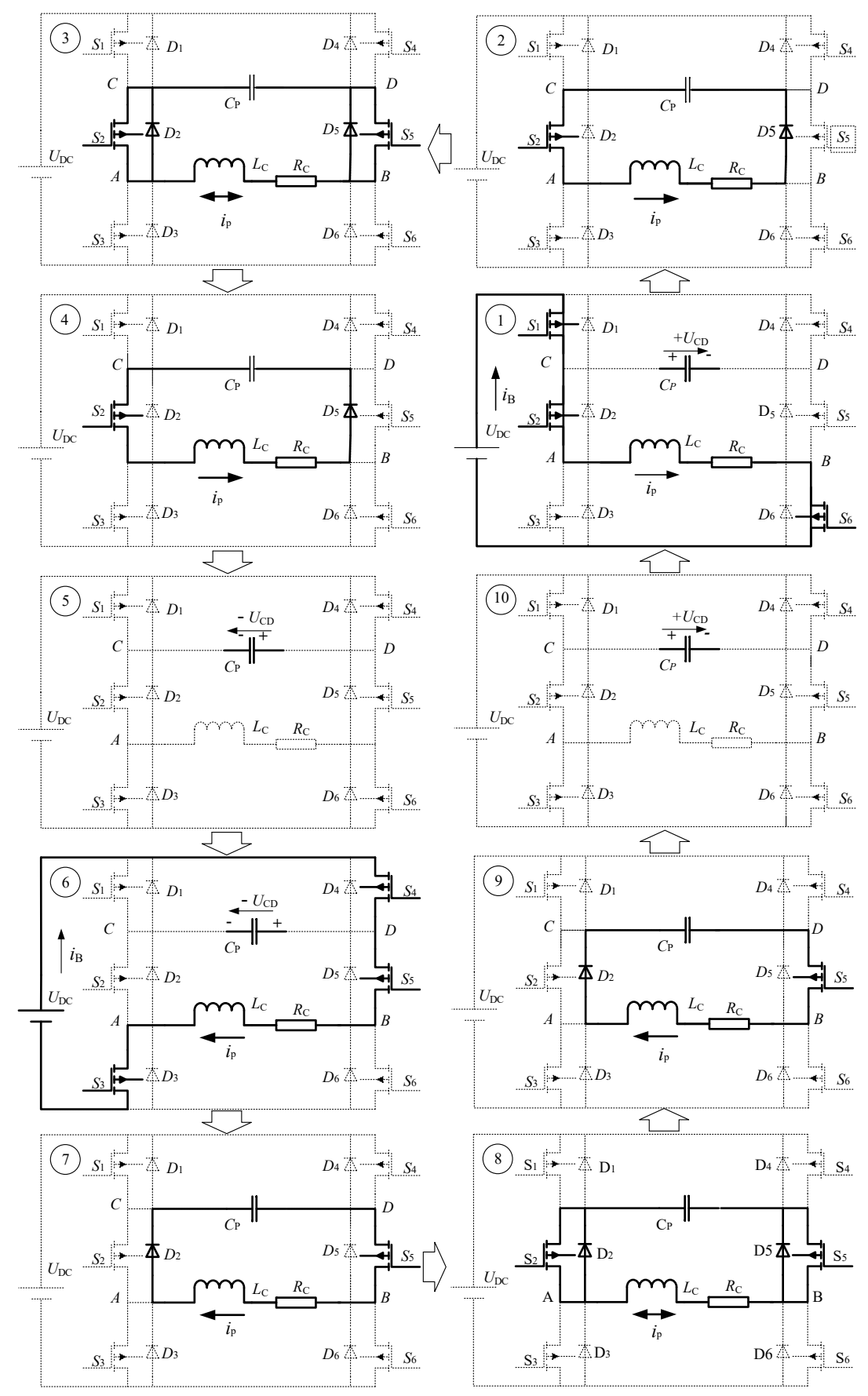

Figure 5. State transitions of the TSEIST power converter.

The waveforms of the converter are shown in Figure 6 with the state numbers. State (10) is the shutdown state of the previous period. $S_{1-6}$ are all turned off, and no energy is transmitted to the secondary. State (1) is identical to the energy injection stage. $S_{1}, S_{2}$, and $S_{6}$ are turned on, and $U_{D C}$ is 
connected to $L_{1}$. The current $i_{\mathrm{p}}$ increases nearly linearly, and energy is injected into the primary coil. The equivalent circuit in this state is shown in Figure 2b. Thus:

$$
\left\{\begin{array}{l}
U_{\mathrm{DC}}=L_{\mathrm{p}} \frac{d i_{\mathrm{p}}}{d t}+L_{m} \frac{d i_{\mathrm{m}}}{d t} \\
0=-L_{\mathrm{m}} \frac{d i_{\mathrm{m}}}{d t}+L_{\mathrm{s}} \frac{d i_{\mathrm{s}}}{d t}+R i_{\mathrm{s}} \\
0=-i_{\mathrm{p}}+i_{\mathrm{m}}+i_{\mathrm{s}}
\end{array} .\right.
$$

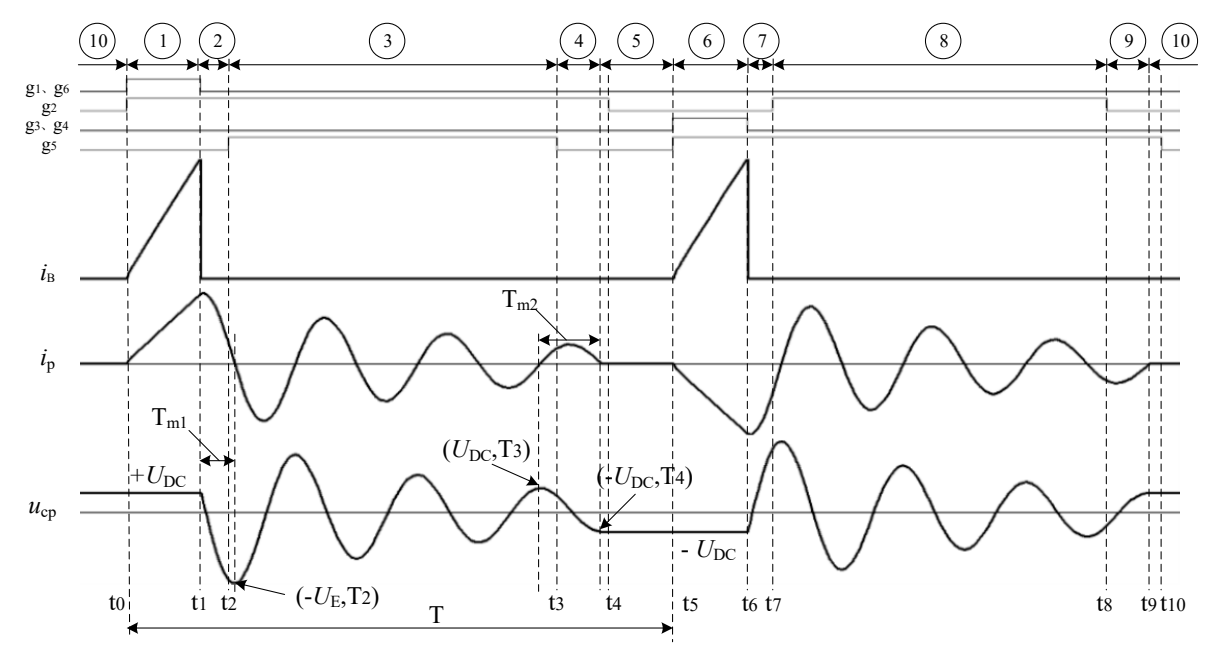

Figure 6. The waveforms of the bus current, primary current and tank capacitance voltage of the TSEIST converter.

Assuming $t_{0}=0$, with the boundary conditions $i_{\mathrm{p}}(0)=i_{\mathrm{m}}(0)=i_{\mathrm{s}}(0)=0$ and Equation (1), we obtain:

$$
\left\{\begin{array}{l}
i_{\mathrm{p}}=\frac{U_{\mathrm{DC}}}{L} t+\frac{k^{2} U_{\mathrm{DC}}}{R}\left(1-e^{-\alpha t}\right) \\
i_{\mathrm{m}}=\frac{U_{\mathrm{DC}}}{L} t-\frac{k(1-k) U_{\mathrm{DC}}}{R}\left(1-e^{-\alpha t}\right), \\
i_{\mathrm{s}}=\frac{k U_{\mathrm{DC}}}{R}\left(1-e^{-\alpha t}\right)
\end{array},\right.
$$

where $\alpha=R /(1-k)^{2} L, \alpha$ is the attenuation factor that expresses the energy consumption of the load. Assuming $\tau_{1}=t_{1}-t_{0}$, the primary current $i_{\mathrm{p}}$ at the end of this state can be written as:

$$
i_{\mathrm{p}}\left(\tau_{1}\right)=\frac{U_{\mathrm{DC}}}{L} \tau_{1}+\frac{k^{2} U_{\mathrm{DC}}}{R}\left(1-e^{-\alpha \tau_{1}}\right) .
$$

State (2) is a transitional state where the converter switches from the energy injection stage to the self-tuning stage. Compared with state (1), $S_{1}$ and $S_{6}$ are turned off in this state. Therefore, $i_{\mathrm{p}}$ flows to $C_{\mathrm{p}}$ through $\mathrm{D}_{5}$ instead; $U_{\mathrm{DC}}$ stops working; and the energy stored in $C_{\mathrm{p}}$ in the previous cycle is added into this cycle. Compared with state (3), $S_{5}$ has to be turned on to ensure $i_{\mathrm{p}}$ flows bi-directionally to allow the system to enter state (3). Since $i_{\mathrm{p}}$ continues to flow forward before the $T_{2}$ moment, $\mathrm{D}_{5}$ is turned on. Thus, the time period $\left[t_{1}, T_{2}\right]$ is defined as a time margin $T_{m 1}$ for turning on $S_{5}$. In this interval, $S_{5}$ is under a soft switching condition.

State (3) is the self-tuning stage. At the $t_{2}$ moment, $S_{5}$ is turned on in soft switching, and $i_{\mathrm{p}}$ flows bi-directionally. In this stage, the system begins to self-tune and the energy continues to transmit to the secondary coil. As the energy is consumed, the amplitude of $u_{\mathrm{cp}}$ decreases exponentially. The duration of this state is related to the coupling coefficient $k$. The detailed analysis about the self-tuning time is discussed in Section 3.3. Since both magnetic energy and electric energy exist in this period, a transitional state is needed following state (3).

State (4) is a transitional state between the self-tuning stage and the shutdown stage. within this state, $S_{5}$ is turned off; $C_{p}$ is charged through $S_{2}$ and $D_{5}$; and the magnetic energy in $L_{C}$ is converted 
into the electric energy in $C_{\mathrm{p}}$. The system exits from the self-tuning stage after the $T_{4}$ moment, and the remaining energy in the tank is stored in $C_{\mathrm{p}}$. Similarly, since $i_{\mathrm{p}}$ keeps flowing forward in the interval $\left[T_{3}, T_{4}\right], D_{5}$ is turned on, and the interval is defined as a time margin $T_{m 2}$ for turning off $S_{5}$ under the soft switching condition.

The voltage equation in time interval $\left[t_{1}, t_{4}\right]$ is:

$$
0=L_{\mathrm{C}} \frac{d i_{\mathrm{p}}}{d t}+i_{\mathrm{p}} R_{\mathrm{C}}+\frac{1}{\mathrm{C}} \int i_{\mathrm{p}} d t
$$

To solve Equation (8), the boundary conditions should be determined. For convenience, $t_{1}$ is defined as 0 , and thus $i_{\mathrm{p}}(0)=i_{\mathrm{p}}\left(\tau_{1}\right)$ and $i_{\mathrm{p}}^{\prime}(0)=U_{\mathrm{DC}}-R_{\mathrm{C}} i_{\mathrm{p}}\left(\tau_{1}\right) / L_{\mathrm{C}}$ according to Figures $3 \mathrm{~b}, 5$ and 6 . Equation (8) can be solved as:

$$
\left\{\begin{array}{l}
i_{p}=I_{E} e^{-\alpha_{1} t} \sin (\omega t+\beta) \\
u_{c p}=U_{B}+U_{E}\left(e^{-\alpha_{1} t} \sin (\omega t+\beta-\gamma)+\sin (\beta+\gamma)\right)
\end{array}\right.
$$

where:

$$
\left\{\begin{array}{l}
I_{\mathrm{E}}=\frac{\sqrt{\left[U_{B}-\frac{R_{c}}{2} i_{p}\left(\tau_{1}\right)\right]^{2}+\left[\omega L_{c} i_{p}\left(\tau_{1}\right)\right]^{2}}}{\omega L_{c}} \\
U_{E}=\frac{I_{E}}{C_{p} \sqrt{\alpha_{1}^{2}+\omega^{2}}} \\
\beta=\arctan \frac{2 \omega L_{c} i_{p}\left(\tau_{1}\right)}{2 U_{B}-R_{c} i_{p}\left(\tau_{1}\right)} \\
\gamma=\arctan \frac{\omega}{\alpha_{1}} \\
\omega=\sqrt{\frac{1}{L_{c} C_{p}}-\left(\frac{R_{c}}{2 L_{c}}\right)^{2}} \\
\alpha_{1}=\frac{R_{C}}{2 L_{C}}
\end{array}\right.
$$

The resonant frequency $\omega$ can be simplified to $\omega=\frac{1}{\sqrt{L_{C} C_{p}}}$.

State (5) is the shutdown stage. In this stage, $S_{1-6}$ are all switched off. The remaining energy is stored in the capacitor $C_{\mathrm{p}}$, and thus $i_{\mathrm{p}}=0$ and $u_{\mathrm{cp}}=-U_{\mathrm{DC}}$.

In states (6-(10), the system works similarly as in states (1)-(5), except that the directions of the voltages and currents are in reverse, which will therefore not be explained again.

\subsection{Calculation of the Self-Tuning Maintenance Time}

Because of the low coupling coefficient, the energy injected into the primary coil cannot be transferred to the secondary coil in one resonant cycle. As shown in Figure 6, the self-tuning stage is maintained for around three cycles. The self-tuning maintenance time varies with the coupling coefficient $k$.

To calculate the self-tuning maintenance time, the voltage waveform of $C_{p}$ in the positive energy transmission period is drawn and shown in Figure 7. To show the waveform with complete cycles, the missing parts of the sinusoidal waveform are shown in bold dash line. Here, $U_{E}$ is the amplitude of the decayed sinusoidal voltage $u_{\mathrm{cp}}, T_{\mathrm{C}}$ is the period of the sinusoidal wave, $\alpha_{1}$ is the decay factor, and $U_{\mathrm{DC}}$ is the voltage of $u_{\mathrm{cp}}$ at the end of the self-tuning period.

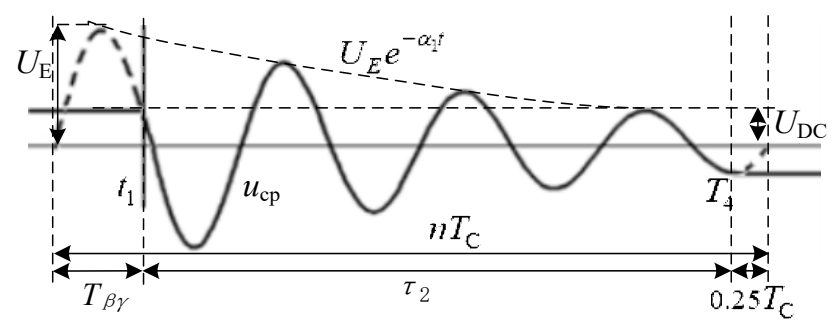

Figure 7. The waveform of the voltage of the tank capacitor. 


\subsubsection{Number of Resonance Cycles}

As shown in Figure $7, u_{\mathrm{cp}}$ is a decayed sinusoid curve with an envelope line $U_{E} e^{-\alpha_{1} n t}$. Based on Equation (9), we obtain:

$$
U_{E} e^{-\alpha_{1} n T_{\mathrm{C}}}=U_{\mathrm{DC}}
$$

and:

$$
n=\left[\frac{1}{\alpha_{1} T_{\mathrm{C}}} \ln \frac{U_{E}}{U_{\mathrm{DC}}}\right]
$$

where [.] is the integer function. Note that the number of the resonance cycles must be an integer.

\subsubsection{Leading Angle $T_{\beta \gamma}$}

The leading angle $T_{\beta \gamma}$ is related to $\beta$ and $\gamma$, and can be calculated by Equation (10). Thus:

$$
T_{\beta \gamma}=\frac{(\beta+\gamma) T_{C}}{2 \pi} .
$$

The self-tuning period time should be:

$$
\tau_{2}=n T_{\mathrm{C}}-T_{\beta \gamma}-0.25 T_{\mathrm{C}}
$$

\subsubsection{Time Margin for State Change}

As $T_{2}$ is the first zero point of $i_{\mathrm{p}}, T_{m 1}$ can be calculated by Equation (9):

$$
i_{p}\left(T_{m 1}\right)=I_{E} e^{-\alpha_{1} T_{m 1}} \sin \left(\omega T_{m 1}+\beta\right)=0 .
$$

Thus:

$$
T_{m 1}=\frac{\pi-\beta}{\omega} .
$$

As shown in Figure 6 , the interval $\left[T_{3}, T_{4}\right]$ is maintained for half a cycle. Thus:

$$
T_{m 2}=\frac{\pi}{\omega} .
$$

\subsection{Power Control}

From Equation (6), when the energy injection stage ends, the magnetic energy in the primary coil can be expressed as:

$$
W_{\mathrm{m}}\left(\tau_{1}\right)=\frac{1}{2} L\left(\frac{U_{\mathrm{DC}}}{L} \tau_{1}-\frac{k(1-k) U_{\mathrm{DC}}}{R}\left(1-e^{-\alpha \tau_{1}}\right)\right)^{2}
$$

The second item can be ignored compared to the first item; thus:

$$
W_{\mathrm{m}}\left(\tau_{1}\right)=\frac{1}{2 L}\left(U_{\mathrm{DC}} \tau_{1}\right)^{2} .
$$

where $W_{\mathrm{m}}\left(\tau_{1}\right)$ is the energy that should be transmitted in the positive energy transmission period $T$. The power of the converter is:

$$
P=\frac{1}{2 L \mathrm{~T}}\left(U_{\mathrm{DC}} \tau_{1}\right)^{2} .
$$

Equation (20) shows that the power can be controlled by controlling the energy injection period $\tau_{1}$. 


\subsection{Transistor Control Strategy Design}

\subsubsection{Switch Control Function for the Self-Tuning Period}

During the self-tuning period, there is a key moment to exit the self-tuning stage. The key moment is determined by the situation of $i_{\mathrm{p}}, u_{\mathrm{cp}}$, and whether the energy transfer period is positive or negative. The variables $I_{\mathrm{m}}, U_{m}$, and $P_{m}$ are defined as situation parameters, which can be generated as a binary signal. Thus:

$$
\begin{aligned}
& I_{m}= \begin{cases}1 & i_{p} \geq 0 \\
0 & i_{p}<0\end{cases} \\
& U_{\mathrm{m}}= \begin{cases}1 & u_{c p m} \leq U_{D C} \\
0 & u_{c p m}>U_{D C}\end{cases} \\
& P_{\mathrm{m}}= \begin{cases}1 & \text { positive energy injection period } \\
0 & \text { reverse energy injection period }\end{cases}
\end{aligned}
$$

so, the actual situation of the system can be described by the situation function $D$ :

$$
D=f\left(\mathrm{I}_{m}, U_{\mathrm{m}}, P_{\mathrm{m}}\right)=\left\{\begin{array}{l}
D_{p}=I_{m}+U_{\mathrm{m}}+P_{\mathrm{m}} \\
D_{r}=\bar{I}_{\mathrm{m}}+U_{\mathrm{m}}+\bar{P}_{\mathrm{m}}
\end{array}\right.
$$

where "-" indicates a non-operation. The $D$ function determines when the system exits the self-tuning resonance. Here, $D_{\mathrm{p}}$ is the exit condition for the positive period and $D_{\mathrm{r}}$ denotes for the negative period.

\subsubsection{Control Logic Block and Control Strategy}

The block diagram of the control logic is shown in Figure 8. It is composed of the voltage processing unit, current processing unit, and program processor of STM32. In Figure $8, \tau_{1}$ is the variable that controls the output power, and $\tau_{3}$ is the variable that controls the shutdown duration, which can be canceled as needed. The voltage signal and the current signal from the sensors are sent to the voltage and current processing units to determine the variables $U_{\mathrm{m}}$ and $I_{\mathrm{m}}$ according to Equation (21). In the control logic software unit, a $P_{\mathrm{m}}$ counter is set for the variable $P_{\mathrm{m}}$. According to the variables $I_{\mathrm{m}}, U_{\mathrm{m}}$, and $P_{\mathrm{m}}$, the $D$ function calculation unit calculates the value of the situation function $D$ according to Equation (22).

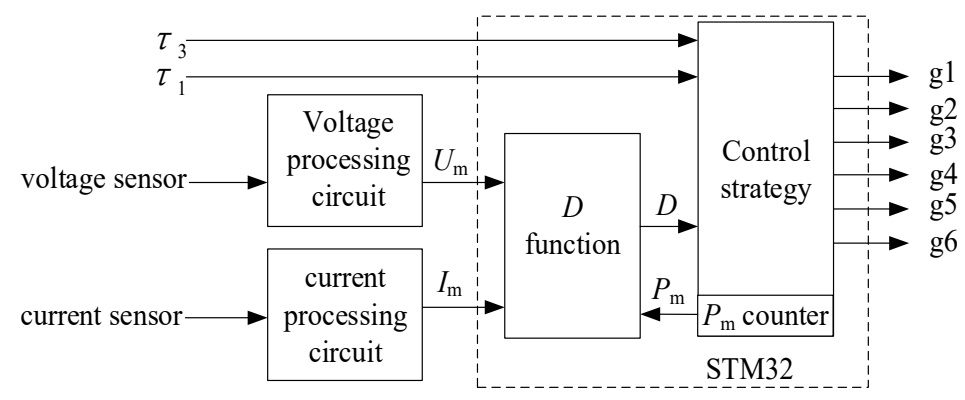

Figure 8. Block diagram of the control logic.

The control strategy generates the control signals $g_{1-6}$, according to the states in Section 3.2., step-by-step to control the switches. The state duration time $\Delta t_{i}(i=0,1,2,3,4)$ is determined by $\tau_{1}$, $\tau_{3}, T_{m 1}, T_{m 2}$, and $D$, as shown in Table 1 . The control strategy is a repetitive state transition loop under the control of the STM32 processor. 
Table 1. State duration time.

\begin{tabular}{cc}
\hline State Duration Time & Calculation Method \\
\hline$\Delta t_{0}$ & $\Delta t_{0}=t_{5}-t_{4}=\tau_{3}$ \\
$\Delta t_{1}$ & $\Delta t_{1}=t_{1}-t_{0}=\tau_{1}$ \\
$\Delta t_{2}$ & $\Delta t_{2}=t_{2}-t_{1}, 0<\Delta t_{2}<T_{m 1}$ \\
$\Delta t_{3}$ & $\Delta t_{3}=t_{3}-t_{2}$, determined by $D_{p}, D_{r}$. \\
$\Delta t_{4}$ & $\Delta t_{4}=t_{4}-t_{3}, 0<\Delta t_{4}<T_{m 2}$ \\
\hline
\end{tabular}

\section{Experimental Prototype Design}

To verify our theoretical analysis of the TSEIST system, a prototype was built for experimental verification.

\subsection{Magneto-Electric System Design}

As shown in Figure 9, two rectangular pads $(460 \mathrm{~mm} \times 370 \mathrm{~mm}$ ) were designed for primary and secondary coil pads, with a base layer, a ferrite core layer, and a copper coil layer. An organic glass layer was stuck onto the coil for protection. The primary coil had 43 turns, and the turn ratio of the coils was 1:1. The other parameters are listed in Table 2.

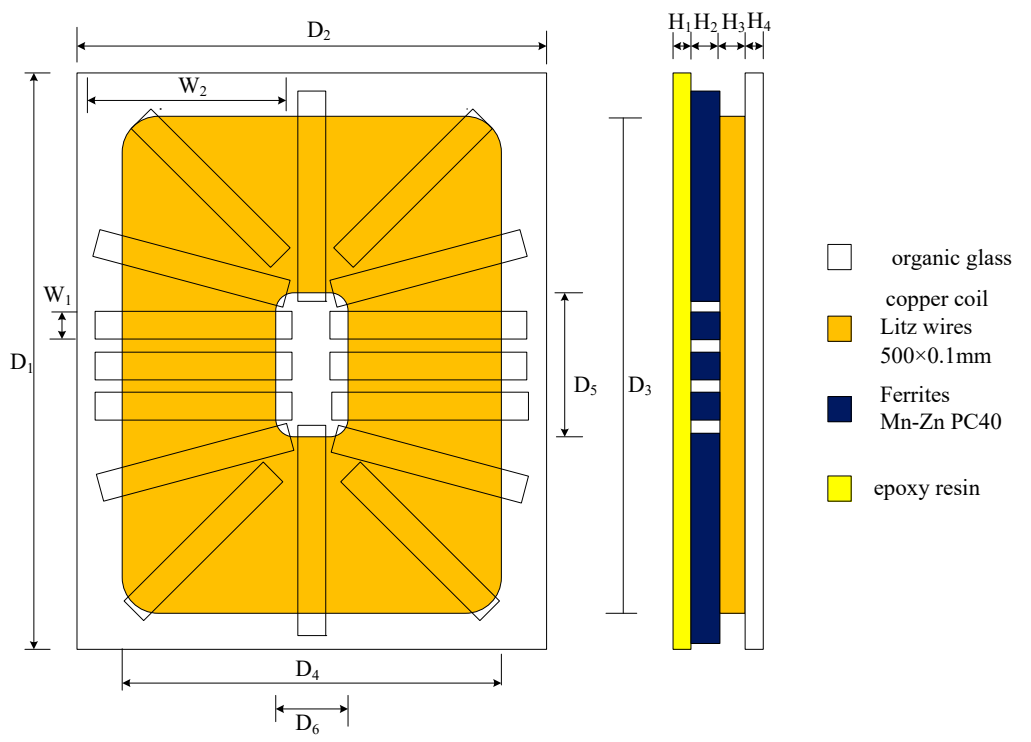

Figure 9. Structure of the coil pads.

Table 2. Parameters of the pads.

\begin{tabular}{cccccc}
\hline $\boldsymbol{D}_{\mathbf{1}}$ & $\boldsymbol{D}_{\mathbf{2}}$ & $\boldsymbol{D}_{\mathbf{3}}$ & $\boldsymbol{D}_{\mathbf{4}}$ & $\boldsymbol{D}_{\mathbf{5}}$ & $\boldsymbol{D}_{\mathbf{6}}$ \\
\hline $460 \mathrm{~mm}$ & $370 \mathrm{~mm}$ & $440 \mathrm{~mm}$ & $350 \mathrm{~mm}$ & $160 \mathrm{~mm}$ & $80 \mathrm{~mm}$ \\
\hline $\boldsymbol{H}_{\mathbf{1}}$ & $\boldsymbol{H}_{\mathbf{2}}$ & $\boldsymbol{H}_{\mathbf{3}}$ & $\boldsymbol{H}_{\mathbf{4}}$ & $\boldsymbol{W}_{\mathbf{1}}$ & $\boldsymbol{W}_{\mathbf{2}}$ \\
\hline $5 \mathrm{~mm}$ & $10 \mathrm{~mm}$ & $5 \mathrm{~mm}$ & $3 \mathrm{~mm}$ & $20 \mathrm{~mm}$ & $150 \mathrm{~mm}$ \\
\hline
\end{tabular}

The coupling coefficient varies with the gap between the two coils, as shown in Figure 10. When the gap varies from 50 to $210 \mathrm{~mm}$, the coupling coefficient varies from 0.51 to 0.06 , respectively. This range covers the range of which in a real EV charging system, 0.1-0.33 [18]. 


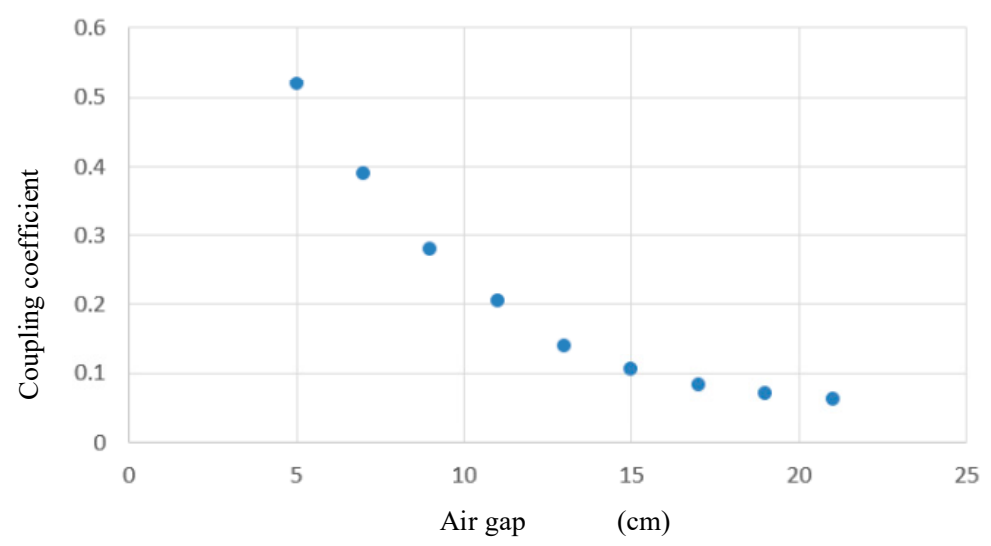

Figure 10. Coupling coefficient versus air gap.

\subsection{Power Converter}

Based on the topology shown in Figure 4, the prototype of the power converter was built as shown in Figure 11. The main parameters of the converter prototype are given in Table 3.

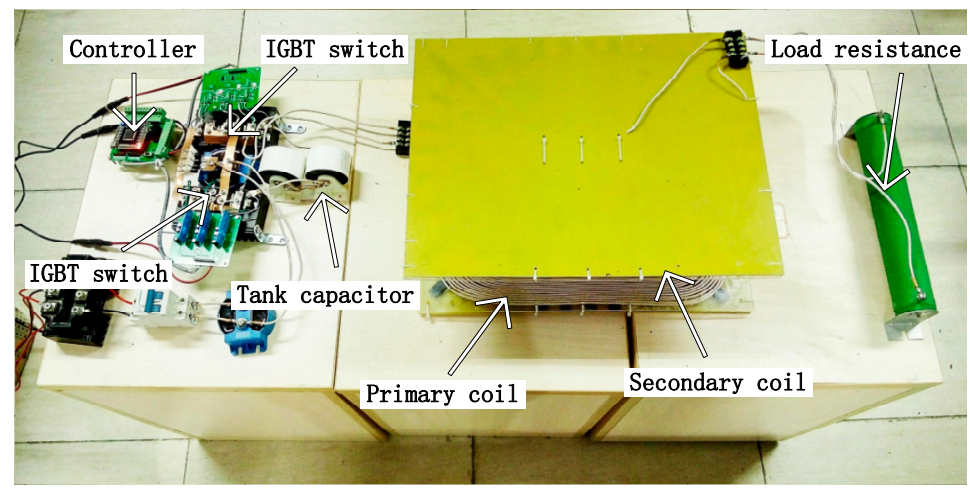

Figure 11. The prototype of the TSEIST power converter system.

Table 3. Main parameters of the power converter.

\begin{tabular}{cc}
\hline Parameter/Part & Value \\
\hline$U_{\mathrm{DC}}$ & $300 \mathrm{~V}$ \\
$C_{\mathrm{p}}$ & $0.44 \mathrm{uF}$ \\
$L_{1}, L_{2}$ & $640 \mathrm{uH}$ \\
$R$ & $50 \Omega$ \\
$\mathrm{S}_{1}-\mathrm{S}_{6}$ & IXFN56N90 \\
\hline
\end{tabular}

\section{Experimental Verification}

\subsection{Characteristics of the TSEIST ICPT System}

A simulation was conducted using SABER and several experiments were completed under the condition of $\tau_{1}=50 \mu \mathrm{s}, \tau_{3}=50 \mu \mathrm{s}$, and $k=0.5$. The simulation and experimental results are shown in Figure 12a,b, respectively. The results agreed well with the analysis in Figure 6.

In the experimental results, we found that the bus current $i_{\mathrm{B}}$ and the primary current $i_{\mathrm{p}}$ increase linearly in the energy injection stage $\tau_{1}$, which shows that the primary inductor is completely decoupled from the resonant tank. The power source injects energy into the primary inductor independently, which coincides with our theoretical analysis. The bus current $i_{\mathrm{B}}$ only exists during the energy injection period $\tau_{1}$. This means that $U_{\mathrm{DC}}$ injects energy only during the energy injection period, without energy backflow, reducing the capacity of the power source. More than two cycles of $i_{\mathrm{p}}$ and $u_{\mathrm{cp}}$ occur in 
the self-tuning period. Compared with $i_{\mathrm{B}}$, the frequency of the resonant tank is about three times greater than that of the power converter. This shows that the proposed converter can operate at a lower switching frequency than the resonance tank frequency, which can reduce the switching loss.
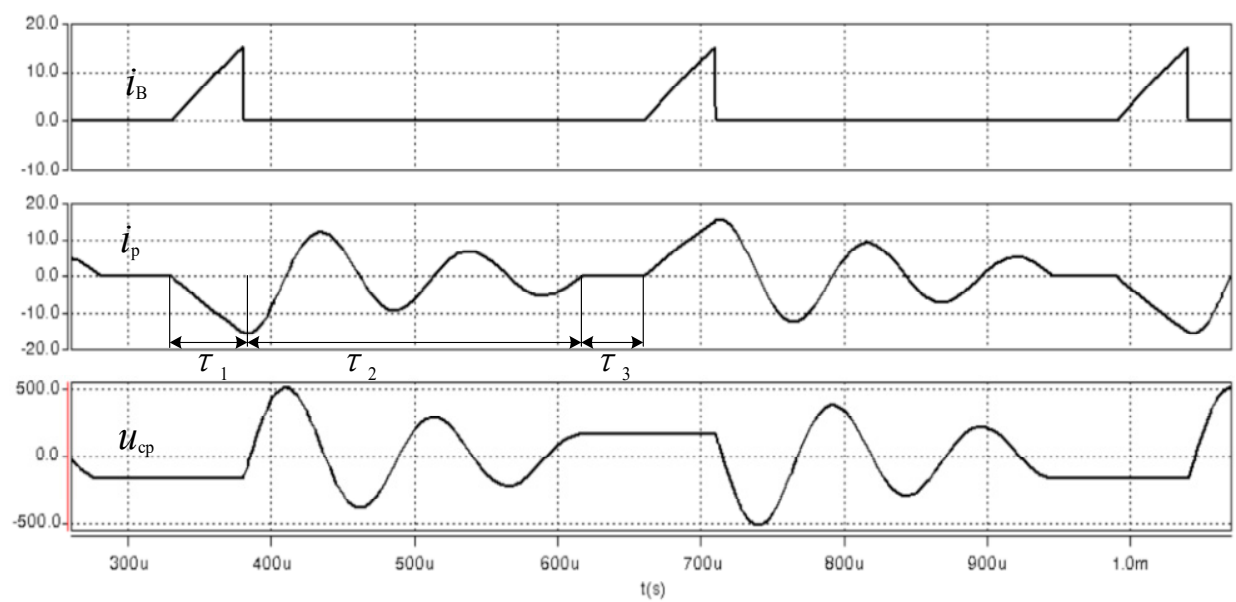

(a)

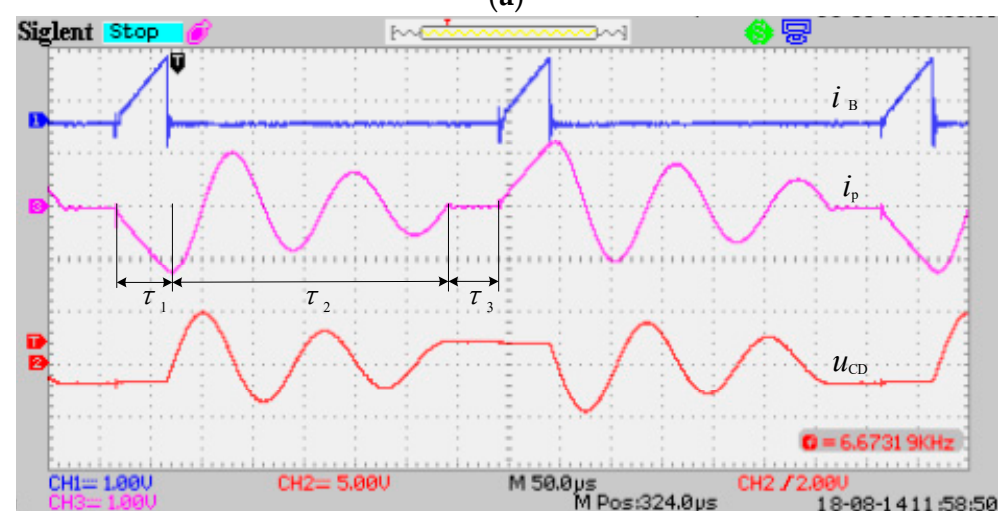

(b)

Figure 12. Results of bus current, primary coil current, and capacitor voltage (a) Simulation results (b) Experimental results (bus current in blue, primary coil current in purple, and capacitor voltage in red line).

\subsection{Power Control}

The power can be controlled by the energy injection period $\tau_{1}$. A comparison between the theoretical and experimental power results is provided in Figure 13. The theoretical results were calculated in MATLAB based on Equations (5)-(20). In Equation (20), $T$ was determined as $T=\tau_{1}+\tau_{2}+\tau_{3}$. As $\tau_{1}$ increases from 25 to $45 \mu \mathrm{s}$, the theoretical power increases from 65 to $210 \mathrm{~W}$ and the experimental power increases from 59 to $199 \mathrm{~W}$. The experimental curve is slightly lower than the calculated curve. This may be due to the coil resistance being ignored in the calculation process.

The experimental results show that, unlike other power control methods, the TSEIST system can control the power easily through the energy injection time. 


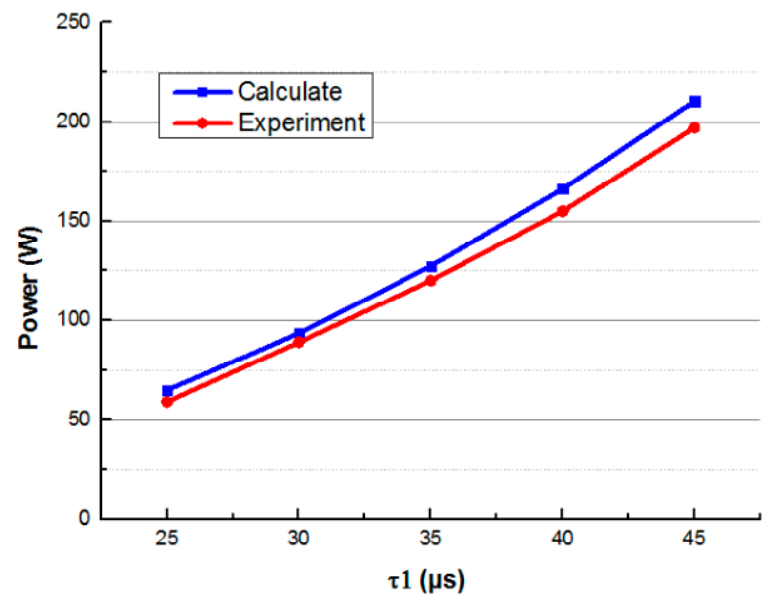

Figure 13. The output power versus energy injecting time $\tau_{1}$ at $k=0.5$.

\subsection{Resonant Frequency}

The theoretical and experimental results of the frequency are shown in Figure 14. As $k$ changed from 0.1 to 0.4 , the theoretical and experimental resonant frequencies changed from $9.77 \mathrm{kHz}$ to $10.6 \mathrm{kHz}$, and $9.1 \mathrm{kHz}$ to $10 \mathrm{kHz}$, respectively. The experimental curve is some lower than the calculated curve.

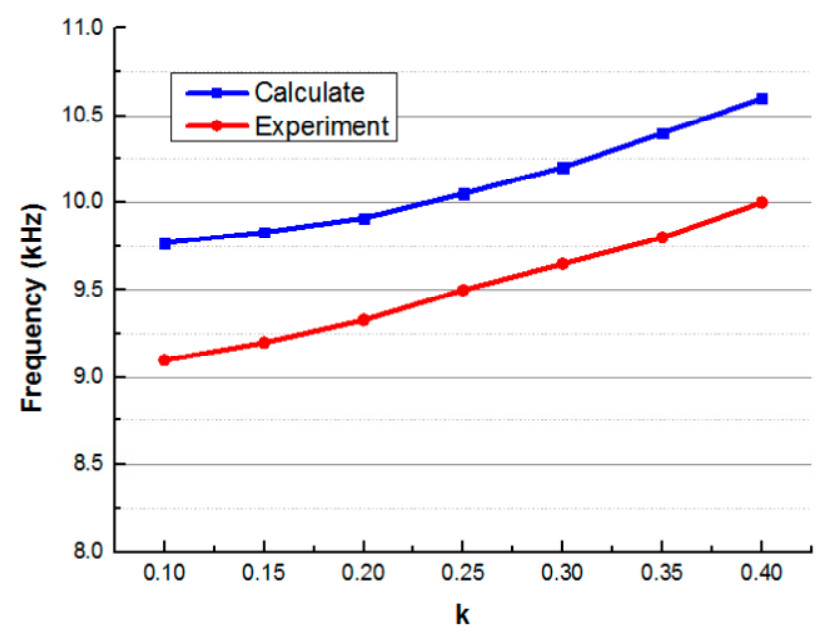

Figure 14. The resonant frequency versus coupling coefficient $k$.

\subsection{Soft Switching}

The driving voltages, voltage drops and currents of switches $S_{1}, S_{2}$, and $S_{3}$, are shown in Figure 15. As shown in Figure 15a, at the point when the driving voltage $g_{1}$ (the blue curve) jumped upward, the current $i_{\mathrm{s} 1}$ (the red curve) is zero. $\mathrm{S}_{1}$ is turned on under the ZCS condition. At the point when $g_{1}$ jumps downward, the voltage $u_{\mathrm{ds} 1}$ (the yellow curve) of $S_{1}$ is zero. $S_{1}$ is turned off under the ZVS condition.

The operation of $S_{2}$ is more complicated. It is switched twice during a working period, as shown in Figure $15 \mathrm{~b}$. When the voltage $g_{2}$ (the blue curve) jumped upward at the first time, $u_{\mathrm{ds} 2}$ (green curve) is zero, and $\mathrm{S}_{2}$ is turned on in ZVS. When $g_{2}$ jumped downward at the first time, the $u_{\mathrm{ds} 2}$ is zero as well and $S_{2}$ is turned off in ZVS. When $g_{2}$ jumped upward at the second time, the current $i_{\mathrm{s} 2}$ (in red curve) is zero, and $S_{2}$ is turned on in ZCS. When $g_{2}$ jumped downward at the second time, $u_{\mathrm{ds} 2}$ and $i_{\mathrm{s} 2}$ are both zero, and $\mathrm{S}_{2}$ is turned off in ZVS and ZCS. 


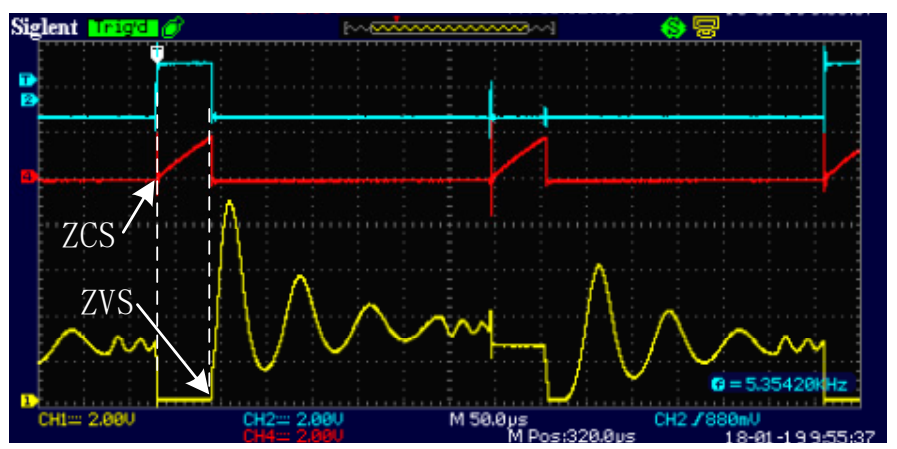

(a)

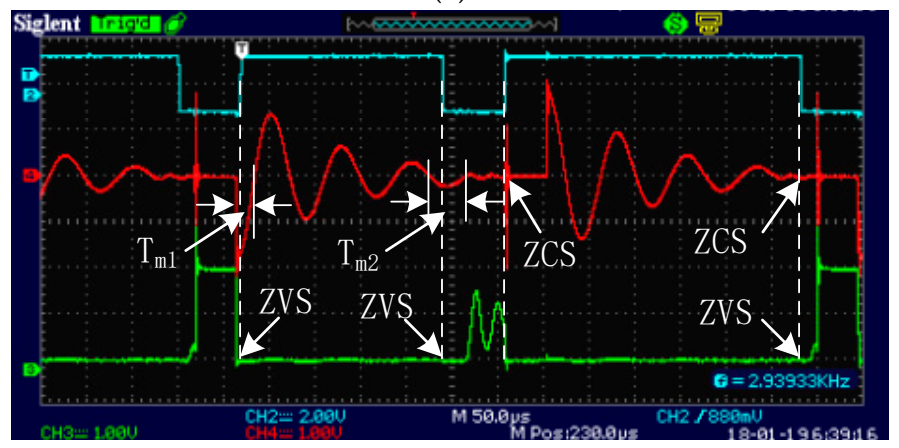

(b)

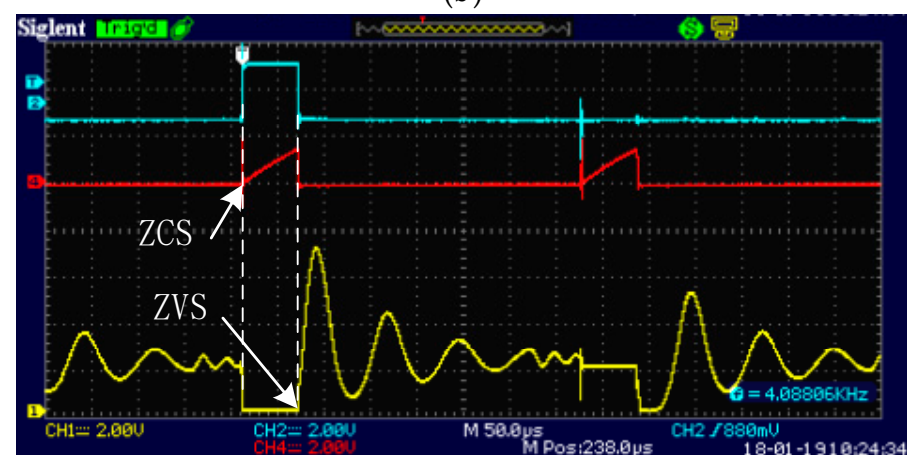

(c)

Figure 15. Operating waves of switches (a) $S_{1},\left(\right.$ b) $S_{2}$, and (c) $S_{3}$ in the experiments.

In Figure $15 b$, the time margin $T_{m 1}$ corresponds to state $(7)$ in Figure 5 and interval $\left[t_{1}, T_{2}\right]$ in Figure 6. $T_{\mathrm{m} 2}$ corresponds to state (9) in Figure 5 and the interval $\left[T_{3}, T_{4}\right]$ in Figure 6 . In these time margins, $D_{2}$ is in the "on" state, and $S_{2}$ is under the ZVS condition. The time margins allow the switches to be turned on or off within a time period, but not at a critical time moment, which coincides with the theoretical analysis.

As shown in Figure 15c, at the point when the driving voltage $g_{3}$ (the blue curve) jumped upward, $\mathrm{S}_{3}$ is turned on in ZCS. At the point when $g_{3}$ jumped downward, the voltage $u_{\mathrm{ds} 3}$ (the yellow curve) of $S_{3}$ is zero and $S_{3}$ is turned off in ZVS. The operating waves of $S_{4}, S_{5}$, and $S_{6}$ are similar to $S_{1}, S_{2}$, and $S_{3}$, respectively.

\subsection{Power and Efficiency}

The efficiency of the magneto-electric system is related to the coupling coefficient, copper resistance, core loss, and other factors [30]. As this research only evaluates the characteristics of the power converter, the efficiency of the magneto-electric system is not considered. $P_{\text {in }}, P_{\text {op }}, P_{\mathrm{os}}, \eta_{\mathrm{p}}$, and $\eta_{\mathrm{s}}$ are shown in Table 4 , in which $P_{\text {in }}$ is the input power, $P_{\mathrm{op}}$ is the output power of power supply (measured at the input of the primary pad), $P_{\text {os }}$ is the output power (measured at the output of the secondary coil), $\eta_{\mathrm{p}}$ is the efficiency of the power convertor that is derived from $P_{\text {op }}$ divided by $P_{\text {in }}$, 
and $\eta_{\mathrm{s}}$ is the total efficiency, which is derived from $P_{\mathrm{os}}$ divided by $P_{\text {in }}$ and contains the efficiency of the magneto-electric system. For comparison, the input power $P_{\text {in }}$ was all set as $350 \mathrm{~W}$. The data were measured using a power analyzer (WT500, Yokogawa Co., Tokyo, Japan).

Table 4. Output power and efficiencies for different coupling coefficients.

\begin{tabular}{cccccc}
\hline $\boldsymbol{k}$ & $\mathbf{0 . 5}$ & $\mathbf{0 . 4}$ & $\mathbf{0 . 2 5}$ & $\mathbf{0 . 1 5}$ & $\mathbf{0 . 1}$ \\
\hline$P_{\text {in }}(\mathrm{W})$ & 350 & 350 & 350 & 350 & 350 \\
$P_{\mathrm{op}}(\mathrm{W})$ & 342 & 341.6 & 340.6 & 338.8 & 335.7 \\
$P_{\mathrm{os}}(\mathrm{W})$ & 327.6 & 326.6 & 324.5 & 314.3 & 303.5 \\
$\eta_{\mathrm{p}}(\%)$ & 97.7 & 97.6 & 97.3 & 96.8 & 95.9 \\
$\eta_{\mathrm{s}}(\%)$ & 93.6 & 93.3 & 92.7 & 89.8 & 86.7 \\
\hline
\end{tabular}

In Table 4 , the converter efficiency $\eta_{\mathrm{p}}$ is maintained at a high level and decreases slightly with a decreasing coupling coefficient. The high efficiency may be due to switches working under soft switching conditions, the converter frequency lower than the resonant frequency, and no backflow current to the source. The total efficiency $\eta_{\mathrm{s}}$ is also higher, but decreases apparently with the decrease in the coupling coefficient. When $k=0.5, \eta_{\mathrm{s}}$ is $93.6 \%$, and when $k=0.1, \eta_{\mathrm{s}}$ is $89.6 \%$. This phenomenon can be explained by the fact that as the coupling coefficient decreases, the transmission efficiency of the magneto-electric system decreases, resulting in a decrease in the overall efficiency.

\section{Conclusions}

In this paper, a TSEIST power converter was proposed and theoretically analyzed. In the proposed power converter system, the primary inductor is separated from the resonant tank in the energy injection stage, and the power source is isolated from the resonant tank during the self-tuning stage. Therefore, in this system, the converter is decoupled from the resonant tank and the resonant tank can automatically track the resonant frequency. The converter can operate at a lower switching frequency than the resonance tank frequency, reducing the switching loss. In this system, switching time margins were applied to ensure all switches in the converter operate under soft switching conditions, reducing the complexity of the switch control strategy and the switching losses. Since the energy injection stage can be independently controlled, the output power of the power converter can be easily controlled. On the other hand, as the system avoids energy backflow and the energy injection period varies with the self-tuning period, the input power is automatically adjusted with the coupling coefficient, and the power capacity rating of the converter is reduced to a low level. Simulations were done to verify the theoretical analysis first. And a prototype of an ICPT system with a TSEIST power converter was designed and fabricated to verify the theoretical and simulation results. The experimental results show that the prototyped ICPT system can work at a high efficiency within a large range of coupling coefficients.

Author Contributions: conceptualization, L.C.; methodology, L.C.; software, J.H.; validation, L.C., J.H. and W.W.; formal analysis, W.C., J.H. and M.G.; investigation, L.C., J.H. and W.W.; resources, W.C. and M.G.; data curation, L.C., J.H. and M.G.; writing-original draft preparation, L.C.; writing-review and editing, M.G.; visualization, M.G.; supervision, W.C.; project administration, W.C.; funding acquisition, W.C.

Funding: This research was funded by National Natural Science Foundation of China (NSFC), grant number 51777177; NSFC grant number 51707168; Key Projects of Fujian Collaborative Innovation Center for R\&D of Coach and Special Vehicle, grant number 2016AYF002; and Guizhou Science and Technology Department, grant number LKS[2011]19.

Conflicts of Interest: The authors declare no conflict of interest.

\section{References}

1. Wu, H.H.; Gilchrist, A.; Sealy, K.D.; Bronson, D. A High Efficiency 5 kW Inductive Charger for EVs Using Dual Side Control. IEEE Trans. Ind. Inform. 2012, 8, 585-595. [CrossRef] 
2. García, X.T.; Vázquez, J.; Roncero-Sánchez, P. Design, Implementation Issues and Performance of an Inductive Power Transfer System for Electric Vehicle Chargers with Series-series Compensation. IET Power Electron. 2015, 8, 1920-1930. [CrossRef]

3. Lu, Y.; Ma, D.B. Wireless Power Transfer System Architectures for Portable or Implantable Applications. Energies 2016, 9, 1087. [CrossRef]

4. Jiang, C.; Chau, K.T.; Liu, C.; Lee, C.H.T. An Overview of Resonant Circuits for Wireless Power Transfer. Energies 2017, 10, 894. [CrossRef]

5. Kim, C.G.; Seo, D.H.; You, J.S.; Park, J.H.; Cho, B.H. Design of a Contactless Battery Charger for Cellular Phone. IEEE Trans. Ind. Electron. 2001, 48, 1238-1247. [CrossRef]

6. Ibrahim, M.; Pichon, L.; Bernard, L.; Razek, A.; Houivet, J.; Cayol, O. Advanced Modeling of a 2-kw Series-series Resonating Inductive Charger for Real Electric Vehicle. IEEE Trans. Veh. Technol. 2015, 64, 421-430. [CrossRef]

7. Hwang, K.; Cho, J.; Kim, D.; Park, J.; Kwon, J.H.; Kwak, S.I.; Park, H.H.; Ahn, S. An Autonomous Coil Alignment System for the Dynamic Wireless Charging of Electric Vehicles to Minimize Lateral Misalignment. Energies 2017, 10, 315. [CrossRef]

8. Lin, X.; Stefanopoulou, A.G.; Li, Y.; Anderson, R.D. State of Charge Imbalance Estimation for Battery Strings Under Reduced Voltage Sensing. IEEE Trans. Control Syst. Technol. 2015, 23, 1052-1062. [CrossRef]

9. Boys, J.T.; Covic, G.A.; Green, A.W. Stability and Control of Inductively Coupled Power Transfer Systems. IEEE Proc. Electr. Power Appl. 2000, 147, 37-43. [CrossRef]

10. Acero, J.; Carretero, C.; Lope, I.; Alonso, R.; Lucia, Ó.; Burdio, J.M. Analysis of the Mutual Inductance of Planar-Lumped Inductive Power Transfer Systems. IEEE Trans. Ind. Electron. 2013, 60, 410-420. [CrossRef]

11. Yang, D.; Ren, J.; Liu, D.; Hu, P. Tuning of Mid-range Wireless Power Transfer System Based on Delay-iteration Method. IET Power Electron. 2016, 9, 1563-1570. [CrossRef]

12. Villa, J.L.; Sallan, J.; Osorio, J.F.S.; Llombart, A. High-Misalignment Tolerant Compensation Topology for ICPT Systems. IEEE Trans. Ind. Electron. 2012, 59, 945-951. [CrossRef]

13. Zheng, C.; Ma, H.; Lai, J.S.; Zhang, L. Design Considerations to Reduce Gap Variation and Misalignment Effects for the Inductive Power Transfer System. IEEE Trans. Power Electron. 2015, 30, 6108-6119. [CrossRef]

14. Do-Hyeon, K.; Dukju, A. Self-tuning LCC Inverter Using PWM-Controlled Switched Capacitor for Inductive Wireless Power Transfer. IEEE Trans. Ind. Electron. 2018, 66, 3983-3992. [CrossRef]

15. Hsu, J.U.W.; Hu, A.P. Determining the Variable Inductance Range for an LCL Wireless Power Pick-up. In Proceedings of the 2007 IEEE Conference on Electron Devices and Solid-State Circuits, Tainan, China, 20-22 December 2007; pp. 489-492. [CrossRef]

16. Kamineni, A.; Covic, G.A.; Boys, J.T. Self-Tuning Power Supply for Inductive Charging. IEEE Trans. Power Electron. 2017, 32, 3467-3479. [CrossRef]

17. Kennedy, H.; Bodnar, R.; Lee, T.; Redman-White, W. A Self-Tuning Resonant-Inductive-Link Transmit Driver Using Quadrature Symmetric Delay Trimmable Phase-Switched Fractional Capacitance. IEEE J. Solid-State Circuits 2018, 53, 1694-1707. [CrossRef]

18. Matysik, J.T. The Current and Voltage Phase Shift Regulation in Resonant Converters with Integration Control. IEEE Trans. Ind. Electron. 2007, 54, 1240-1242. [CrossRef]

19. Gati, E.; Kampitsis, G.; Manias, S. Variable Frequency Controller for Inductive Power Transfer in Dynamic Conditions. IEEE Trans. Power Electron. 2017, 32, 1684-1696. [CrossRef]

20. Gati, E.; Kampitsis, G.; Stavropoulos, I.; Papathanassiou, S.; Manias, S. Wireless Phase_Locked Loop Control for Inductive Power Transfer Systems. In Proceedings of the IEEE Applied Power Electronics Conference and Exposition (APEC), Charlotte, NC, USA, 15-19 March 2015; pp. 1601-1607. [CrossRef]

21. Xu, L.; Chen, Q.; Ren, X.; Wong, S.C.; Tse, C.K. Self-Oscillating Resonant Converter with Contactless Power Transfer and Integrated Current Sensing Transformer. IEEE Trans. Power Electron. 2016, 32, 4839-4851. [CrossRef]

22. Namadmalan, A. Self-Oscillating Tuning Loops for Series Resonant Inductive Power Transfer Systems. IEEE Trans. Power Electron. 2016, 31, 7320-7327. [CrossRef]

23. Yan, K.; Chen, Q.; Hou, J.; Ren, X.; Ruan, X. Self-Oscillating Contactless Resonant Converter with Phase Detection Contactless Current Transformer. IEEE Trans. Power Electron. 2014, 29, 4438-4449. [CrossRef] 
24. Li, H.L.; Hu, A.P.; Covic, G.A. Development of a Discrete Energy Injection Inverter for Contactless Power Transfer. In Proceedings of the 2008 3rd IEEE Conference on Industrial Electronics and Applications, Singapore, 3-5 June 2008; pp. 1757-1761. [CrossRef]

25. Li, H.L.; Hu, A.P.; Covic, G.A. A Direct AC-AC Converter for Inductive Power-Transfer Systems. IEEE Trans. Power Electron. 2012, 27, 661-668. [CrossRef]

26. Matysik, J.T. A New Method of Integration Control with Instantaneous Current Monitoring for Class D Series-Resonant Converter. IEEE Trans. Ind. Electron. 2006, 53, 1564-1576. [CrossRef]

27. Moghaddami, M.; Sundararajan, A.; Sarwat, A.I. A Power-Frequency Controller with Resonance Frequency Tracking Capability for Inductive Power Transfer Systems. IEEE Trans. Ind. Appl. 2018, 54, 1773-1783. [CrossRef]

28. Dede, E.J. Improving the Efficiency of IGBT Series-resonant Inverters using Pulse Density Modulation. IEEE Trans. Ind. Electron. 2011, 58, 979-987. [CrossRef]

29. Fujita, H.; Akagi, H. Pulse-density-modulated Power Control of a 4 kw, $450 \mathrm{kHz}$ Voltage-source Inverter for Induction Melting Applications. IEEE Trans. Ind. Appl. 1996, 32, 279-286. [CrossRef]

30. Lin, F.Y.; Covic, G.A.; Boys, J.T. Evaluation of Magnetic Pad Sizes and Topologies for Electric Vehicle Charging. IEEE Trans. Power Electron. 2015, 30, 6391-6407. [CrossRef]

(C) 2019 by the authors. Licensee MDPI, Basel, Switzerland. This article is an open access article distributed under the terms and conditions of the Creative Commons Attribution (CC BY) license (http:/ / creativecommons.org/licenses/by/4.0/). 